Academic Platform Journal of Engineering and Science

\title{
SWARA-WASPAS Metodolojisine Dayalı Tedarikçi Seçimi: Türkiye'de Demir-Çelik Endüstrisi Örneği
}

\author{
${ }^{* 1}$ Merve Cengiz Toklu, ${ }^{2}$ Gültekin Çağıl, ${ }^{3}$ Elif Pazar, ${ }^{4}$ Rümeysa Faydalı \\ ${ }^{1}$ Sakarya Üniversitesi, Mühendislik Fakültesi, Endüstri Mühendisliği Bölümü, Sakarya, Türkiye, mtoklu@ sakarya.edu.tr, \\ ${ }^{2}$ Sakarya Üniversitesi, Mühendislik Fakültesi, Endüstri Mühendisliği Bölümü, Sakarya, Türkiye, cagil@ sakarya.edu.tr, \\ ${ }^{3}$ Sakarya Üniversitesi, Mühendislik Fakültesi, Endüstri Mühendisliği Bölümü, Sakarya, Türkiye, elifpzr@gmail.com, \\ ${ }^{4}$ Sakarya Üniversitesi, Mühendislik Fakültesi, Endüstri Mühendisliği Bölümü, Sakarya, Türkiye, rumeysafaydali@gmail.com,
}

Tedarik zinciri yönetiminin öncelikli süreçlerinden birisi de tedarikçi seçimidir. İşletmelerin rekabet avantajı sağlamaları için kabul edilebilir kalite sınırını aşmadan düşük maliyetle üretim yapmaları gerekmektedir. Bu da iyi yönetilen bir tedarik zinciri ile mümkün olur. İşletmeler tedarikçi seçimi yaparken öncelikle değerlendirme kriterlerini tespit etmeli, daha sonra da alternatifler arasından en uygun olan tedarikçinin seçimini yapmalıdır. Bu çalışma tedarik zinciri yönetiminin bir parçası olan tedarikçi seçimi konusunu ele alır. Çalışmanın amacı, Sakarya ilinde bulunan bir ağır metal fabrikasının üretim hattında kullanılan makine parçasının taşlanması için daha önce en az bir kez çalışılmış 3 tedarikçi arasından en uygun tedarikçinin seçilmesidir. Bu doğrultuda öncelikle bir araştırma ekibi kurulmuş ve bu ekip tarafindan değerlendirme kriterleri belirlenmiştir. Kriter ağırlıklarının belirlenmesi için SWARA yöntemi, alternatifleri değerlendirmek ve sıralamak için ise WASPAS yöntemi kullanılmıştır. İşletme için en uygun alternatif belirlenmiştir.

Anahtar Kelimeler: Tedarikçi seçimi, SWARA, WASPAS, çok kriterli karar verme

\section{Supplier Selection Based on SWARA-WASPAS Methodology: The Case of the Iron Steel Industry in Turkey}

\footnotetext{
${ }^{* 1}$ Merve Cengiz Toklu, ${ }^{2}$ Gültekin Çăgıl, ${ }^{3}$ Elif Pazar, ${ }^{4}$ Rümeysa Faydalı

${ }^{1}$ Sakarya University, Faculty of Engineering, Department of Industrial Engineering, Sakarya, Turkey, mtoklu@ sakarya.edu.tr

${ }^{2}$ Sakarya University, Faculty of Engineering, Department of Industrial Engineering, Sakarya, Turkey, cagil@ sakarya.edu.tr

${ }^{3}$ Sakarya University, Faculty of Engineering, Department of Industrial Engineering, Sakarya, Turkey, elifpzr@gmail.com

${ }^{4}$ Sakarya University, Faculty of Engineering, Department of Industrial Engineering, Sakarya, Turkey, rumeysafaydali@gmail.com
}

\begin{abstract}
One of the priority processes of supply chain management is supplier selection. Companies need to produce at low cost without exceeding the acceptable quality limit to achieve competitive advantage. This is possible with a well-managed supply chain. Companies should first determine the evaluation criteria when selecting suppliers, and then select the most suitable supplier from among the alternatives. This study deals with supplier selection, which is part of supply chain management. The aim of the study is to select the most suitable supplier among the 3 suppliers who have worked at least once in order to grind a machine part used in production line of a heavy metal company in Sakarya province. For this reason, a research team has been established and the evaluation criteria have been determined. The SWARA method was used to determine the criterion weights, and the WASPAS method was used to evaluate the alternatives. The most suitable alternative for the company has been identified.
\end{abstract}

Keywords: Supplier selection, SWARA, WASPAS, multi-criteria decision making 


\section{GİRIŞ}

İşletmelerin rekabet üstünlüğü sağlayarak varlıklarını sürdürebilmeleri için üretim maliyetlerini düşürmeleri, tedarik riskini azaltmaları, stok miktarlarını, iş süreçlerini ve çevrim sürelerini en uygun hale getirmeleri gerekmektedir. İşletmeler, tedarik zincirinin etkin yönetimi sayesinde değişen müşteri taleplerine kısa sürede cevap verebilir. Tedarik zinciri yönetimi, tedarik zincirinde yer alan tüm adımlardaki toplam maliyetin en aza indirilmesi adına üretici ve tedarikçi arasında gerçekleştirilen çalışmaların tamamıdır [1-2].

Tedarikçi seçimi, tedarik zinciri yönetimi konusu içinde incelenen bir konu olup tedarik zincirinin etkin bir biçimde yönetilmesine önemli katkı sağlar. Çünkü seçilen tedarikçi, işletmelerin başarısını doğrudan etkilemektedir [3].

Tedarikçi seçiminin temel amacı, bir işletmenin ihtiyacını karşılamak üzere belirlenmiş kriterler çerçevesinde en uygun ürün ve/veya hizmet sağlayıcını belirlemektir. Uygun tedarikçinin seçilmesi sayesinde işletme başarısı büyük oranda artış gösterecektir. Ancak tedarikçi seçim sürecinde yapılacak hatalar ürün kalitesini, teslimat sürelerini ve dolayısı ile üretimi doğrudan etkileyerek ek maliyetlerin oluşmasına neden olacaktır. $\mathrm{Bu}$ durum işletmenin uzun dönemli performansını da olumsuz olarak etkileyecektir [4].

İşletmeler tedarikçilerini sadece ürün ve/veya hizmet satın aldıkları bir kaynak olarak değil, üretim süreçlerinde etkin rol oynayan bir paydaş olarak değerlendirmektedir. Bu yaklaşım, tedarikçi seçim sürecini daha da önemli kılarak, bu süreç için farklı yöntemlerin geliştirilmesine neden olmaktadır. Tedarikçi seçimi probleminde karar verme süreci kalitatif ve kantitatif farklı bir çok kriterin değerlendirilmesini içerdiği için literatürde çok kriterli bir karar verme süreci olarak değerlendirilmektedir.

$\mathrm{Bu}$ çalışmada, tedarikçi seçim problemine SWARA (Stepwise Weight Assessment Ratio Analysis-Kademeli Ağırlık Değerlendirme Oran Analizi) ve WASPAS (Weighted Aggregated Sum Product Assessment-Ağırlıklandırılmış Bütünleşik Toplam Çarpım Değerlendirmesi) yöntemlerinin birlikte kullanılması ile çözüm geliştirilmesi amaçlanmıştır. Tedarikçi seçim probleminde farklı çok kriterli karar verme yöntemleri kullanılmaktadır. SWARA ve WASPAS yöntemleri, hem tedarikçi seçimi hem de farklı problemlerdeki alternatiflerin sıralanması ve seçimi için kullanılmaktadır.

Alimardani ve ark. [5] çevik tedarik zinciri yönetiminde tedarikçi seçim sürecinde SWARA ve VIKOR yöntemlerini birlikte kullanmışlardır. Kouchaksaraei ve ark. [6] fabrika yeri seçiminde kriterleri değerlendirmek için SWARA yöntemini kullanırken, COPRAS yöntemini alternatifleri değerlendirmek için kullanmıştır. Ghorabaee ve ark. [7] yeşil tedarikçi seçiminde Aralık Tip-2 Bulanık WASPAS yöntemini kullanmıştır. Zavadskas ve ark. [8] bina iç ortamında en uygun seçimi gerçekleştirmek için WASPAS yöntemini kullanmıştır. Aytaç Adalı ve Tuş Işık [3] tedarikçi seçiminde SWARA ve WASPAS yöntemlerini kullanmıştır. Çakır ve ark. [9] çalışmalarında özel alışveriş sitelerini değerlendirerek en iyi alternatifi tespit etmeyi amaçlamıştır. $\mathrm{Bu}$ amaç için SWARA ve WASPAS yöntemlerini kullanmışlardır. Zarbakhshnia ve ark. [10] çalışmalarında üçüncü parti lojistik firması seçiminde SWARA ve COPRAS yöntemlerini kullanmışlardır. Literatürde yer alan bazı çalışmalarda tedarikçi seçim probleminde, SWARA ve WASPAS yöntemlerinin birlikte kullanılması bu çalışma ile benzerlik göstermekle birlikte, bu çalışma, tedarikçi değerlendirme kriterleri ve uygulamanın yapıldığı sektör ile mevcut çalışmalardan ayrilmaktadır.

Çalışmanın bundan sonraki kısmı genel olarak şu bölümlerden oluşmaktadır: İkinci bölümde SWARA ve WASPAS yöntemleri anlatılmıştır. Üçüncü bölümde ise Sakarya İlinde bulunan bir ağır metal fabrikasında gerçekleştirilen uygulama anlatılmıştır. Sonuçlar bölümünde uygulamanın sonuçları tartışılarak gelecek çalışmalardan bahsedilmiştir.

\section{METODOLOJİ}

\subsection{Kademeli Ăğırlık Değerlendirme Oran Analizi (SWARA) Yöntemi}

Keršuliene ve ark. [11] tarafından geliştirilen SWARA yöntemi, birden fazla kriter içeren karar verme problemlerinde kriter ağırlıklarının belirlenebilmesi için kullanılmaktadır. SWARA yöntemi, kriterler ve bu kriterlerin birbirlerine göre öncelikleri hakkında bilgi verebilmekte olup kriter ağırlıklarının bilindiği durumlar için de kullanılabilmektedir [3]. SWARA yönteminin adımları aşağıda özetlenmiştir $[9,11]$;

Adım 1: Problemin çözümünde yer alacak kriter seti belirlenir ve en önemli kriterden daha az öneme sahip kritere doğru sıralama yapılır. Problemde $n$ tane kriterin $\left(C_{j}\right.$, $\mathrm{j}=1,2, \ldots \mathrm{n})$ ve $\mathrm{k}$ tane karar vericinin $\left(\mathrm{KV}_{\mathrm{k}}, \mathrm{k}=1,2, \ldots, \mathrm{k}\right)$ bulunduğu varsayılmaktadır. Eğer birden fazla karar verici (KV) mevcutsa her bir karar vericinin bireysel olarak yaptığ 1 değerlendirme sonucu, ölçütler azalan düzeyde sıralanır ve ölçütlerin geometrik ortalaması alınarak genel bir sıralama oluşturulur.

Adım 2: Kriterlerin önem ağırlıkları belirlenir. Bunun için ikinci kriterden $(\mathrm{j}+1)$ başlayarak her bir kriter kendisinden önceki kriter (j) ile mukayese edilir. Kriterlerin birbirlerine göre karşılaştırmalı önemi sj olarak gösterilmektedir.

Adım 3: $\mathrm{k}_{\mathrm{j}}$ katsayıları aşağıdaki formülle hesaplanmaktadır. Kriterlerin ortak sıralanmasında en önemli kriterin katsayısı 1 olmalıdır. Formül, Eşitlik (1)'de gösterilmiştir.

$k_{j}= \begin{cases}1 & \text { ĕger } j=1 \\ s_{j}+1 & \text { ĕger } j>1\end{cases}$ 
Adım 4: Önem vektörü ( $\left.w_{j}\right)$, Eşitlik (2) ile hesaplanır.

$w_{j}= \begin{cases}1 & \text { ĕ } \text { er } j=1 \\ \frac{w_{j-1}}{k_{j}} & \text { ĕ } \text { er } j>1\end{cases}$

Adım 5: Kriter ağırlıklarının değeri $\left(q_{j}\right)$, Eşitlik (3) ile bulunur.

$q_{j}=\frac{w_{j}}{\sum w_{j}}$

Adım 6: Her bir karar verici için ayrı ayrı hesaplanan $\mathrm{q}_{\mathrm{j}}$ değerlerinin aritmetik ortalamaları alınarak kriterlerin nihai ağırlıkları belirlenir.

\section{2. Ăğırlıklandırılmış Bütünleşik Toplam Çarpım Değerlendirmesi (WASPAS) Yöntemi}

Çok kriterli karar verme yöntemlerinden birisi olan ve alternatiflerin değerlendirilerek sıralanması için kullanılan WASPAS yöntemi, 2012 yılında Zavadskas ve ark. [12] tarafindan geliştirilmiştir. WASPAS yönteminin adımları aşağıda özetlenmiştir [12-14].

$\mathrm{Bu}$ yöntemde ele alınan problemde $m$ tane alternatif $\mathrm{A}_{\mathrm{i}}(\mathrm{i}=1,2, \ldots, \mathrm{m})$ ve $\mathrm{n}$ tane kriter $C_{\mathrm{j}}(\mathrm{j}=1,2, \ldots, \mathrm{n})$ olarak belirtilmektedir.

Adım 1: Problemde yer alan alternatiflerin problemdeki kriterler temel alındığındaki performanslarını gösteren karar matrisinin $(\mathrm{X})$ oluşturulması.

$X=\left[x_{i j}\right]_{m x n}=\left[\begin{array}{cccc}x_{11} & x_{12} & \ldots & x_{1 m} \\ x_{21} & x_{22} & \ldots & x_{2 m} \\ \vdots & \vdots & \ddots & \vdots \\ x_{m 1} & x_{m 2} & \ldots & x_{m n}\end{array}\right]$

$\mathrm{i}=1,2, \ldots, \mathrm{m}$ ve $\mathrm{j}=1,2, \ldots, \mathrm{n}$

Adım 2: Karar matrisinin normalize edilmesi $\left(\bar{x}_{i j}\right)$. Değerlendirme kriterinin maksimizasyon veya minimizasyon olması durumuna göre iki farklı eşitlik kullanılmaktadır.

$\bar{x}_{i j}=\frac{x_{i j}}{\max _{i}\left(x_{i j}\right)} \quad \mathrm{i}=1,2, \ldots, \mathrm{m}$ ve $\mathrm{j}=1,2, \ldots, \mathrm{n}$
$\bar{x}_{i j}=\frac{\min _{i} x_{i j}}{x_{i j}}$
Adım 3: i. alternatifin toplam göreli önemi, Ağırlıklı Toplam Modeli (Weighted Sum Model, WSM) ile Ağırlıklı Çarpım Modeli (Weighted Product Model, WPM)'ne göre ayrı ayrı hesaplanması. WSM' ye göre bir alternatifin toplam göreli önemi $\left(Q_{i}^{(1)}\right)$ ve WPM' ye göre bir alternatifin toplam göreli önemi $\left(Q_{i}^{(2)}\right)$ sirasıyla Eşitlik (7) ve Eşitlik (8) kullanılarak hesaplanır.

$Q_{i}^{(1)}=\sum_{j=1}^{n} \bar{x}_{i j} w_{j}$

$Q_{i}^{(2)}=\prod_{j=1}^{n} \bar{x}_{i j}{ }^{w j}$

Adım 4: Alternatiflerin toplam göreli önemleri, genel bir formül olarak belirlenebilir.

$Q_{i}=\lambda Q_{i}^{(1)}+(1-\lambda) Q_{i}^{(2)}$

$=\lambda \sum_{j=1}^{n}\left(x_{i j}\right) w_{j}+(1-\lambda) \prod_{j=1}^{n}\left(x_{i j}\right)^{w j}, \lambda=0,0.1 \ldots 1$

$Q_{\mathrm{i}}$, WASPAS yönteminde i. alternatifin toplam göreli önemini göstermektedir. $\lambda$ ise WASPAS yönteminde kullanılan bir parametre olup 0 ile 1 arasında değer alır. Hesaplamalarda $\lambda$ değeri karar vericinin görüşüne bırakılır ancak Zavadskas ve ark. [12] $\lambda$ için optimum değeri bulmaya yönelik bir denklem önermişlerdir. Alternatifler $\mathrm{Q}$ değerlerine göre sıralanırlar. En iyi alternatif $\mathrm{Q}$ değeri en yüksek olan alternatiftir.

\section{UYGULAMA}

Bu çalışmada, metodoloji kısmında bahsedilen yaklaşımlar Sakarya ilinde bulunan bir ağır metal fabrikasının tedarikçi değerlendirme sürecinde uygulanmıştır. $\mathrm{Bu}$ firmada, işbirliği yapılacak olan tedarikçiler satın alma bölümü yöneticilerinin deneyimlerine bağlı olarak genellikle maliyet kriteri göz önünde bulundurularak belirlenmektedir. Tedarikçilerle yapılan işbirlikleri uzun vadeli olup yüksek maliyetlerde ürün/hizmet alımı yapılmaktadır. Uygulamanın gerçekleştirildiği firma, asitleme hattına ait bir makine parçasının taşlanması için üç farklı tedarikçi arasından en doğru seçimi yapmayı hedeflemiştir. Bu amaçla, üst düzey yöneticilerden oluşan uzman bir araştırma ekibi kurulmuş ve bu ekip tarafindan değerlendirme kriterleri belirlenmiştir. Her bir kriter farklı öneme sahip olduğundan dolayı SWARA yöntemi ile kriterlerin ağırlıkları belirlenmiştir. Daha sonraki aşamada ise WASPAS yöntemi ile üç alternatif tedarikçi değerlendirilmiş ve en uygun alternatif seçilmiştir. Bu aşamalar Şekil 1'de gösterilmiştir. 


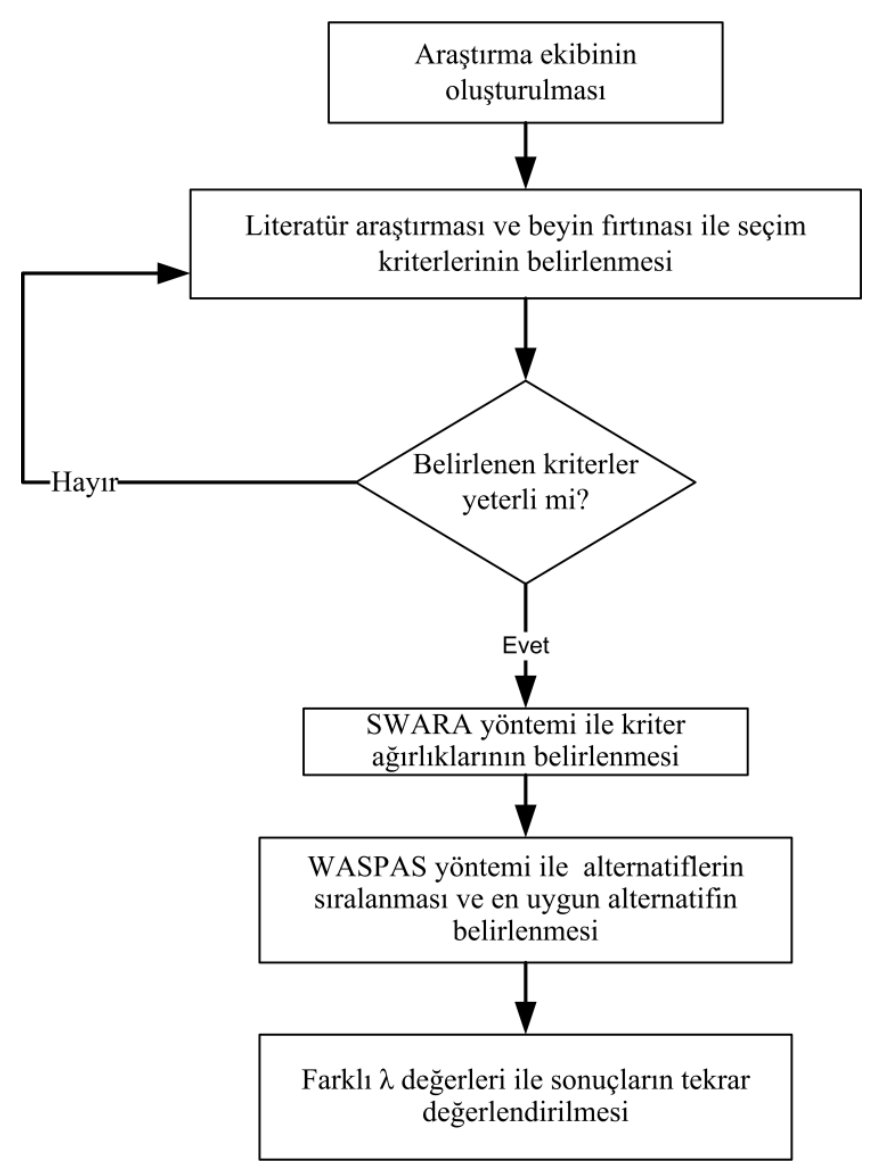

Şekil 1. Uygulama aşamaları

\subsection{Tedarikçi Seçimine İlişkin Kriterlerin Belirlenmesi}

Tedarikçi seçiminde farklı pek çok kriter rol oynamaktadır. Literatürdeki çalışmalar incelendiğinde maliyet, kalite ve teslimat süresi kriterleri en sık kullanılan kriterler arasında yer alır.

Uygulamanın yapıldığı işletmede değerlendirme kriterlerinin belirlenmesi için üç karar verici ile görüşme yapılmıştır. Bu karar vericiler; Bakım Mühendisi, Teknik Satınalma Mühendisi ve Tedarik Zinciri Müdürü'dür.

Karar vericiler ile yapılan görüş̧meler sonucunda; Maliyet Avantaj1, Kalite, Zamanında Teslimat, Tepki Süresi, Tedarikçi Güvenilirliği, Ödeme Koşulları, Talebe Uygunluk, Tedarikçinin Coğrafi Konumu olmak üzere sekiz kriter belirlenmiştir.

Daha sonraki aşamada bu kriterlere ek olarak literatürdeki çalışmalar incelenmiştir. Yapılan inceleme sonucunda sıklıkla kullanılan üç kriter; Malın Sevkiyat Şekli, Geçmiş Dönem Performansı ve Esneklik karar vericilerin de onayı ile daha önce belirlenen kriterlere eklenmiş ve toplamda 11 adet değerlendirme kriteri oluşturulmuştur. Belirlenen kriterler aşağıda kısaca açıklanmıştır.
- Maliyet Avantaj1: Tedarikçiden temin edilen hammadde, yarı mamul veya hizmet maliyetlerinin düşük olmasıdır.

- Kalite: Talep edilen ürünün kabul edilebilir kalite düzeyinde olmasıdır.

- Zamanında Teslimat: Talep edilen ürünün anlaşma dahilindeki sürelerde teslim edilmesidir.

- Tepki Süresi: Acil durumlar karşısında tedarikçinin firmaya en kısa sürede cevap verebilmesidir.

- Tedarikçi Güvenilirliği: Tedarikçi ve firma arasındaki yapılan anlaşmaya tedarikçinin sadık kalmasıdır.

- Ödeme Koşulları: Tedarikçinin, firmaya yapılması gereken ödeme için sunduğu olanaklardır.

- Talebe Uygunluk: Tedarik edilecek olan ürünün talep doğrultusunda olmasıdır.

- Tedarikçinin Coğrafi Konumu: Tedarikçinin firmaya göre en uygun konumda olmasıdır.

- Esneklik: Tedarikçi firmanın değişen arz ve taleplerimize karşı gösterdiği toleranslardır.

- Malın Sevkiyat Şekli: Talep edilen ürünün özelliklerine göre en uygun şekil ve şartlarda sevkiyatın gerçekleştirilmesidir.

- Geçmiş Dönem Performans1: Daha önceden çalışılan tedarikçiler için geçmişteki raporlara bakılarak değerlendirilmesi, daha önce çalıșılmamış tedarikçiler için ise yaptığı çalışmalar incelenerek değerlendirilmesidir.

\subsection{SWARA Yöntemi ile Kriterlerin Önem Derecelerinin Belirlenmesi}

Karar vericiler kriterlerin her birini değerlendirerek puanlandırmıştır. Tablo 1'de verildiği gibi karar vericiler kriterleri en önemliden daha az önemliye doğru sıralamıştır. Birden çok uzman, ölçütleri değerlendirdiği için azalan düzeyde sıralanan ölçütlerin geometrik ortalaması alınarak genel bir sıralama oluşturulmuştur. Örneğin karar verici 1'e göre tedarikçi değerlendirme sürecinde en önemli kriter maliyet avantaj1 (K1) kriteri iken en önemsiz kriter ise geçmiş dönem performansıdır (K10).

Bir sonraki adımda her bir KV'ye göre değerlendirme kriterlerinin göreli önem düzeyleri belirlenmiştir. Bunun için ikinci kriterden $(j+1)$ başlayarak her bir kriter kendisinden önceki kriter (j) ile mukayese edilmiş ve kriterlerin birbirlerine göre karşılaştırmalı önemleri $\left(\mathrm{s}_{\mathrm{j}}\right)$ belirlenmiştir. Eşitlik (1) kullanılarak kriterlerin birbirlerine göre karşılaştırmalı önemlerine ait katsayılar $\left(\mathrm{k}_{\mathrm{j}}\right)$ belirlenmişșir. Eşitlik (2)'den faydalanılarak kriterlere ait önem vektörü $w_{j}$ hesaplanmış ve Eşitlik (3) ile değerlendirme kriterlerine ait ağırlıklar belirlenmiştir. Tüm karar vericiler için aynı adımlar tekrarlanmıştır.

Karar Verici 1, Karar Verici 2 ve Karar Verici 3'e ait değerlendirme sonuçları sırasıyla Tablo 2, Tablo 3 ve Tablo 4 'te gösterilmiştir. 
Tablo 1. Karar Vericilere Göre Değerlendirme Kriterlerinin Önem Sıraları

\begin{tabular}{lccccc}
\hline Kriterler & KV-1 & KV-2 & KV-3 & Geo. Ort. & Siralama \\
\hline Maliyet Avantaj1 (K1) & 1 & 2 & 3 & 1,82 & 2 \\
\hline Kalite (K2) & 2 & 1 & 2 & 1,59 & 1 \\
\hline Zamanında Teslimat (K3) & 4 & 3 & 1 & 2,29 & 3 \\
\hline Tepki Süresi (K4) & 5 & 7 & 4 & 5,19 & 7 \\
\hline Tedarikçi Güvenilirliği (K5) & 6 & 6 & 7 & 6,32 & 6 \\
\hline Ödeme Koşulları (K6) & 3 & 8 & 8 & 5,77 & 5 \\
\hline Talebe Uygunluk (K7) & 8 & 4 & 5 & 5,43 & 10 \\
\hline Tedarikçinin coğrafi konumu (K8) & 9 & 9 & 9 & 9,00 & 8,69 \\
\hline Malın Sevkiyat Şekli (K9) & 10 & 5 & 6 & 11,00 & \\
\hline Geçmiş Dönem Performansı (K10) & 11 & 11 & 11 & & 11 \\
\hline Esneklik (K11) & 7 & 10 & 10 & 8,88 & 9 \\
\hline
\end{tabular}

Tablo 2. Karar Verici 1'e Göre Değerlendirme Kriterlerine Ait Ağırlıklar

\begin{tabular}{llllll}
\hline S1ralama & Kriterler & $\mathrm{s}_{\mathrm{j}}$ & $\mathrm{k}_{\mathrm{j}}$ & $\mathrm{w}_{\mathrm{j}}$ & $\mathrm{q}_{\mathrm{j}}$ \\
\hline 1 & $\mathrm{~K} 2$ & & 1 & 1 & 0,359 \\
\hline 2 & $\mathrm{~K} 1$ & 0,8 & 1,8 & 0,556 & 0,200 \\
\hline 3 & $\mathrm{~K} 3$ & 0,55 & 1,55 & 0,358 & 0,129 \\
\hline 4 & $\mathrm{~K} 4$ & 0,5 & 1,5 & 0,239 & 0,086 \\
\hline 5 & $\mathrm{~K} 7$ & 0,3 & 1,3 & 0,184 & 0,066 \\
\hline 6 & $\mathrm{~K} 6$ & 0,4 & 1,4 & 0,131 & 0,047 \\
\hline 7 & $\mathrm{~K} 5$ & 0,4 & 1,4 & 0,094 & 0,034 \\
\hline 9 & $\mathrm{~K} 9$ & 0,2 & 1,2 & 0,078 & 0,028 \\
\hline 10 & $\mathrm{~K} 11$ & 0,35 & 1,35 & 0,058 & 0,021 \\
\hline 11 & $\mathrm{~K} 8$ & 0,25 & 1,25 & 0,046 & 0,017 \\
\hline
\end{tabular}

Tablo 3. Karar Verici 2'ye Göre Değerlendirme Kriterlerine Ait Ağırlıklar

\begin{tabular}{llllll}
\hline Siralama & Kriterler & $\mathrm{s}_{\mathrm{j}}$ & $\mathrm{k}_{\mathrm{j}}$ & $\mathrm{w}_{\mathrm{j}}$ & $\mathrm{q}_{\mathrm{j}}$ \\
\hline 1 & $\mathrm{~K} 2$ & & 1 & 1,000 & 0,446 \\
\hline 2 & $\mathrm{~K} 1$ & 0,9 & 1,9 & 0,526 & 0,235 \\
\hline 3 & $\mathrm{~K} 3$ & 0,8 & 1,8 & 0,292 & 0,131 \\
\hline 4 & $\mathrm{~K} 4$ & 0,75 & 1,75 & 0,167 & 0,075 \\
\hline 5 & $\mathrm{~K} 7$ & 0,7 & 1,7 & 0,098 & 0,044 \\
\hline 6 & $\mathrm{~K} 6$ & 0,65 & 1,65 & 0,060 & 0,027 \\
\hline 7 & $\mathrm{~K} 5$ & 0,6 & 1,6 & 0,037 & 0,017 \\
\hline 9 & $\mathrm{~K} 9$ & 0,55 & 1,55 & 0,024 & 0,011 \\
\hline 10 & $\mathrm{~K} 11$ & 0,5 & 1,5 & 0,016 & 0,007 \\
\hline 11 & $\mathrm{~K} 8$ & 0,45 & 1,45 & 0,011 & 0,005 \\
\hline
\end{tabular}

Tablo 4. Karar Verici 3'e Göre Değerlendirme Kriterlerine Ait Ağırlıklar

\begin{tabular}{llllll}
\hline Siralama & Kriterler & $\mathrm{s}_{\mathrm{j}}$ & $\mathrm{k}_{\mathrm{j}}$ & $\mathrm{W}_{\mathrm{j}}$ & $\mathrm{q}_{\mathrm{j}}$ \\
\hline 1 & $\mathrm{~K} 2$ & & 1 & 1,000 & 0,440 \\
\hline 2 & $\mathrm{~K} 1$ & 0,85 & 1,85 & 0,541 & 0,238 \\
\hline 3 & $\mathrm{~K} 3$ & 0,8 & 1,8 & 0,300 & 0,132 \\
\hline 4 & $\mathrm{~K} 4$ & 0,75 & 1,75 & 0,172 & 0,075 \\
\hline 5 & $\mathrm{~K} 7$ & 0,7 & 1,7 & 0,101 & 0,044 \\
\hline 6 & $\mathrm{~K} 6$ & 0,65 & 1,65 & 0,061 & 0,027 \\
\hline 7 & $\mathrm{~K} 5$ & 0,6 & 1,6 & 0,038 & 0,017 \\
\hline 9 & $\mathrm{~K} 9$ & 0,55 & 1,55 & 0,025 & 0,011 \\
\hline 10 & $\mathrm{~K} 11$ & 0,5 & 1,5 & 0,016 & 0,007 \\
\hline 11 & $\mathrm{~K} 8$ & 0,45 & 1,45 & 0,011 & 0,005 \\
\hline
\end{tabular}


Her karar verici için ayrı ayrı hesaplanan kriter ağırlıkları $\left(\mathrm{q}_{\mathrm{j}}\right.$ değerleri) kriterler bazında aritmetik ortalamaları alınarak genel kriter ağırlıkları belirlenmiştir. Belirlenen kriter ağırlıkları Tablo 5 'te gösterilmiştir.

Tablo 5. Değerlendirme Kriterlerine Ait Ağırlıklar

\begin{tabular}{ccccc}
\hline Kriterler & KV-1 & KV-2 & KV-3 & Kriter Ağırlılar1 \\
\hline K2 & 0,359 & 0,446 & 0,440 & 0,415 \\
\hline K1 & 0,200 & 0,235 & 0,238 & 0,224 \\
\hline K3 & 0,129 & 0,131 & 0,132 & 0,130 \\
\hline K4 & 0,086 & 0,075 & 0,075 & 0,079 \\
\hline K7 & 0,066 & 0,044 & 0,044 & 0,051 \\
\hline K6 & 0,047 & 0,027 & 0,027 & 0,034 \\
\hline K5 & 0,034 & 0,017 & 0,017 & 0,022 \\
\hline K9 & 0,028 & 0,011 & 0,011 & 0,017 \\
\hline K11 & 0,021 & 0,007 & 0,007 & 0,012 \\
\hline K8 & 0,017 & 0,005 & 0,005 & 0,009 \\
\hline K10 & 0,014 & 0,004 & 0,004 & 0,007 \\
\hline
\end{tabular}

Tablo 5'e göre tedarikçi değerlendirme sürecinde en önemli kriter kalite (K2) kriteri iken, en az öneme sahip kriter ise geçmiş dönem performansı (K10) kriteri olarak belirlenmiştir. $\mathrm{Bu}$ kriterlere ait önem dereceleri ise sirasiyla; 0,415 ve 0,007 'dir.

\subsection{Alternatiflerin Değerlendirilmesi ve Sıralanması İçin WASPAS Yönteminin Uygulanması}

Tedarikçi seçiminde, kriterlerin ağırlıkları belirlendikten sonra 3 alternatif tedarikçi (Alt-1, Alt-2 ve Alt-3) WASPAS yöntemi ile değerlendirilerek seçim süreci tamamlanmıştır. Öncelikle her bir alternatifin değerlendirme kriterleri altında performanslarını gösteren karar matrisleri oluşturulmuştur. Üç karar vericinin verdikleri puanların aritmetik ortalaması alınarak grup kararına ait sonuçlar belirlenmiştir (Tablo 6).

Tablo 6. Grup Kararı Sonucu Elde Edilen Karar Matrisi

\begin{tabular}{lccccc}
\hline Kriterler & $\begin{array}{l}\text { Kriter } \\
\text { Sınıfi }\end{array}$ & Ağırlık & Alt-1 & Alt-2 & Alt-3 \\
\hline Maliyet Avantaj1 (K1) & Max & 0,224 & 55 & 66,67 & 70 \\
\hline Kalite (K2) & Max & 0,415 & 38,33 & 76,67 & 50 \\
\hline $\begin{array}{l}\text { Zamanında Teslimat } \\
\text { (K3) }\end{array}$ & Max & 0,13 & 56,67 & 65 & 50 \\
\hline Tepki Süresi (K4) & Min & 0,079 & 61,67 & 53,33 & 48,33 \\
\hline $\begin{array}{l}\text { Tedarikçi } \\
\text { Güvenilirliği (K5) }\end{array}$ & Max & 0,022 & 60 & 68,33 & 53,33 \\
\hline Ödeme Koşulları (K6) & Max & 0,034 & 65 & 73,33 & 51,67 \\
\hline $\begin{array}{l}\text { Talebe Uygunluk } \\
\text { (K7) }\end{array}$ & Max & 0,051 & 48,33 & 85 & 65 \\
\hline Coğrafi konumu (K8) & Min & 0,009 & 63,33 & 66,67 & 63,33 \\
\hline $\begin{array}{l}\text { Malın Sevkiyat Şekli } \\
\text { (K9) }\end{array}$ & Max & 0,017 & 63,33 & 65 & 60 \\
\hline $\begin{array}{l}\text { Geçmiş Dönem } \\
\text { Performans1 (K10) }\end{array}$ & Max & 0,007 & 60 & 61,67 & 58,33 \\
\hline Esneklik (K11) & Max & 0,012 & 45 & 70 & 58,33 \\
\hline
\end{tabular}

Daha sonra elde edilen karar matrisi, maksimizasyon ve minimizasyon tipindeki kriterler bazında Eşitlik (5) ve (6) ile normalize edilmiştir. Değerler Tablo 7' de gösterilmiştir.
Tablo 7. Normalize Edilmiş Karar Matrisi

\begin{tabular}{lcccc}
\hline Kriterler & Alt-1 & Alt-2 & Alt-3 & $\mathrm{w}_{\mathrm{j}}$ \\
\hline Maliyet Avantaj1 (K1) & 0,79 & 0,95 & 1 & 70 \\
\hline Kalite (K2) & 0,50 & 1 & 0,65 & 76,67 \\
\hline Zamanında Teslimat (K3) & 0,87 & 1 & 0,77 & 65 \\
\hline Tepki Süresi (K4) & 0,78 & 0,91 & 1 & 48,33 \\
\hline Tedarikçi Güvenilirliği (K5) & 0,88 & 1 & 0,78 & 68,33 \\
\hline Ödeme Koşulları (K6) & 0,89 & 1 & 0,70 & 73,33 \\
\hline Talebe Uygunluk (K7) & 0,57 & 1 & 0,76 & 85 \\
\hline Tedarikçinin coğrafi konumu (K8) & 1 & 0,95 & 1 & 63,33 \\
\hline Malın Sevkiyat Şekli (K9) & 0,97 & 1 & 0,92 & 65 \\
\hline Geçmiş Dönem Performansı (K10) & 0,97 & 1 & 0,95 & 61,67 \\
\hline Esneklik (K11) & 0,64 & 1 & 0,83 & 70 \\
\hline & & & &
\end{tabular}

Bir sonraki adımda WSM'ye göre bir alternatifin toplam göreli önemi, kriter değerlerinin ağırlıklı toplamı olarak hesaplanmıştır. WSM'ye göre alternatiflerin toplam göreli önemi $\left(Q_{i}^{(1)}\right)$, Eşitlik (7) ile hesaplanmıştır. Hesaplanan değerler Tablo 8'de gösterilmiştir.

Tablo 8. Ağırlıklı Toplam Modeli (WSM) ile Hesaplanan Alternatiflerin Toplam Göreli Önemleri

\begin{tabular}{lccc}
\hline Kriterler & Alt-1 & Alt-2 & Alt-3 \\
\hline Maliyet Avantaj1 (K1) & 0,18 & 0,21 & 0,22 \\
\hline Kalite (K2) & 0,21 & 0,42 & 0,27 \\
\hline Zamanında Teslimat (K3) & 0,11 & 0,13 & 0,10 \\
\hline Tepki Süresi (K4) & 0,06 & 0,07 & 0,08 \\
\hline Tedarikçi Güvenilirliği (K5) & 0,02 & 0,02 & 0,02 \\
\hline Ödeme Koşulları (K6) & 0,03 & 0,03 & 0,02 \\
\hline Talebe Uygunluk (K7) & 0,03 & 0,05 & 0,04 \\
\hline Tedarikçinin coğrafi konumu (K8) & 0,01 & 0,01 & 0,01 \\
\hline Malın Sevkiyat Şekli (K9) & 0,02 & 0,02 & 0,02 \\
\hline Geçmiş Dönem Performans1 (K10) & 0,01 & 0,01 & 0,01 \\
\hline Esneklik (K11) & 0,01 & 0,01 & 0,01 \\
\hline$Q_{i}^{(1)}$ & 0,68 & 0,98 & 0,80 \\
\hline
\end{tabular}

Daha sonra ise WPM'ye göre bir alternatifin kriter bazındaki performans değerinin kriter ağırlığ kuvvetinin çarpımı olarak hesaplanır. WPM'ye göre alternatiflerin toplam göreli önemi $\left(Q_{i}^{(2)}\right)$, Eşitlik (8) ile hesaplanmıştır. Hesaplanan değerler Tablo 9'da gösterilmiştir.

Tablo 9. Ağırlıklı Çarpım Modeli (WPM) ile Alternatiflerin Toplam Göreli Önemleri

\begin{tabular}{lccc}
\hline Kriterler & Alt-1 & Alt-2 & Alt-3 \\
\hline Maliyet Avantaj1 (K1) & 0,947 & 0,989 & 1,000 \\
\hline Kalite (K2) & 0,750 & 1,000 & 0,837 \\
\hline Zamanında Teslimat (K3) & 0,982 & 1,000 & 0,966 \\
\hline Tepki Süresi (K4) & 0,981 & 0,992 & 1,000 \\
\hline Tedarikçi Güvenilirliği (K5) & 0,997 & 1,000 & 0,995 \\
\hline Ödeme Koşulları (K6) & 0,996 & 1,000 & 0,988 \\
\hline Talebe Uygunluk (K7) & 0,972 & 1,000 & 0,986 \\
\hline Tedarikçinin coğrafi konumu (K8) & 1,000 & 1,000 & 1,000 \\
\hline Malın Sevkiyat Şekli (K9) & 1,000 & 1,000 & 0,999 \\
\hline Geçmiş Dönem Performansı (K10) & 1,000 & 1,000 & 1,000 \\
\hline Esneklik (K11) & 0,995 & 1,000 & 0,998 \\
\hline$Q_{i}^{(2)}$ & 0,657 & 0,981 & 0,782 \\
\hline
\end{tabular}


Bir önceki adımda WSM ve WPM yöntemlerine göre hesaplanan alternatiflerin toplam göreli önemleri $\left(Q_{i}\right)$, Eşitlik (9) ile genelleştirilebilir. Bu genelleştirme sonucu Tablo 10'da gösterilmiştir. Eşitlik (9)'da kullanılan $\lambda$ değeri WASPAS yönteminde kullanılan bir parametre olup 0 ile 1 arasında değer almaktadır. $\lambda=0$ ve $\lambda=1$ olarak alındığında WASPAS yöntemi, sırasıyla WPM ve WSM yöntemlerine dönüşmektedir. Tablo 10 'da görülebileceği gibi $\lambda$ değerinin değiştirilmesi Alt-2>Alt-3>Alt-1 Sırasını değiştirmemektedir. Dolayısı ile $\lambda$ değerinin seçimi sonucu etkilememekte olup $\lambda=0,5$ değeri seçilerek çalışma tamamlanmıştır.

Son adımda, SWARA yönteminden elde edilen ağırlıklar da kullanılarak, alternatiflerin değerlendirilmesi ve sıralanması işlemi gerçekleştirilmiştir. Bu değerlendirme sonucunda en uygun tedarikçi belirlenmiştir. WASPAS yönteminde alternatiflerin sıralaması, $Q_{i}$ değerleri dikkate alınarak yapılmaktadır. En yüksek $Q_{i}$ değerine sahip alternatif, en iyi alternatif olarak seçilmiştir. Dolayısıyla firma için en uygun tedarikçinin, Alt-2 olarak anılan 2 numaralı alternatif tedarikçi olduğu tespit edilmiştir.

Tablo 10. Alternatiflerin Göreli ve Toplam Önem Düzeyleri

\begin{tabular}{ccccc}
\hline & $\lambda$ Değerleri & Alt-1 & Alt-2 & Alt-3 \\
\hline$Q_{i}^{(1)}$ & & 0,6773 & 0,9815 & 0,7951 \\
\hline$Q_{i}^{(2)}$ & & 0,6568 & 0,9810 & 0,7816 \\
\hline $\mathrm{Q}_{0,1}$ & 0,1 & 0,6588 & 0,9811 & 0,7829 \\
\hline $\mathrm{Q}_{0,2}$ & 0,2 & 0,6609 & 0,9811 & 0,7843 \\
\hline $\mathrm{Q}_{0,3}$ & 0,3 & 0,6629 & 0,9812 & 0,7856 \\
\hline $\mathrm{Q}_{0,4}$ & 0,4 & 0,6650 & 0,9812 & 0,7870 \\
\hline $\mathrm{Q}_{0,5}$ & 0,5 & 0,6670 & 0,9812 & 0,7883 \\
\hline $\mathrm{Q}_{0,6}$ & 0,6 & 0,6691 & 0,9813 & 0,7897 \\
\hline $\mathrm{Q}_{0,7}$ & 0,7 & 0,6711 & 0,9813 & 0,7910 \\
\hline $\mathrm{Q}_{0,8}$ & 0,8 & 0,6732 & 0,9814 & 0,7924 \\
\hline $\mathrm{Q}_{0,9}$ & 0,9 & 0,6752 & 0,9814 & 0,7937 \\
\hline $\mathrm{Q}_{1}$ & 1,0 & 0,6773 & 0,9815 & 0,7951 \\
\hline
\end{tabular}

\section{SONUCCLAR}

Artan rekabet koşullarında, firmaların ayakta kalabilmeleri ve yüksek kar payı ile çalışabilmeleri için düşük maliyetle yüksek verimli üretim yapmaları gerekmektedir. Bunu başarmanın ilk basamağı ise tedarikçi seçiminin doğru yapılmasıdır. Tedarikçi seçiminde birden fazla karar vericinin, kriterleri ve tedarikçi alternatiflerini değerlendirmesi aşamasında çok kriterli karar verme yöntemlerine başvurmak, tedarikçi seçimi sürecini kolaylaştırarak daha uygun kararlar verilmesi ile sonuçlanacaktır. Bu çalışmada, tedarikçi seçim probleminin çözümü için SWARA ve WASPAS yöntemleri kullanılmıştır. Öncelikle uzman kişilerden oluşturulan araştırma ekibi değerlendirme kriterlerini belirlemiş, daha sonra yapılan literatür taraması sonucunda mevcut kriterlere üç kriter daha eklenmiştir. Daha sonra kriter ağırlıkları SWARA yöntemi ile belirlenmiştir. Alternatiflerin değerlendirilmesi ve sıralanması ise WASPAS yöntemi ile gerçekleştirilmiştir. WASPAS yönteminden elde edilen sonuçlara göre alternatif tedarikçi firmaların sıralaması Alt2>Alt-3>Alt-1 olarak belirlenmiş olup en uygun tedarikçi olarak Alt-2 seçilmiştir. $\mathrm{Bu}$ çalışma öncesinde, firma tedarikçilerini sadece maliyet avantajı kriterine göre değerlendirmekteydi ve Tablo 6'da da görülebileceği gibi Alt-3 olarak anılan tedarikçi ile çalışmaktaydı. Yapılan çalışma sonucunda sadece maliyet kriterinin değil, farklı kriterlerin de göz önünde bulundurulması ile değerlendirme yapılmış ve tedarikçi olarak Alt-2 seçilmiştir.

Gelecek çalışmalarda, önerilen yaklaşım artan kriter ve alternatif sayılarına göre yeniden uygulanabilir. Aynı zamanda çalışma Bulanık SWARA ve Bulanık WASPAS yöntemleri kullanılarak karar vericilerin net bilgisinin olmadığı durumlarda da tedarikçi seçim sürecini yönetmesi sağlanabilir.

\section{KAYNAKÇA}

[1] G. Akyüz, "Bulanık VIKOR Yöntemi ile Tedarikçi Seçimi," Atatürk Üniversitesi İktisadi ve İdari Bilim. Derg., vol. 26, no. 1, pp. 197-215, 2012.

[2] M. Dağdeviren and E. Erarslan, "PROMETHEE Sıralama Yöntemi ile Tedarikçi Seçimi," Gazi Üniversitesi Mühendislik-Mimarlık Fakültesi Derg., vol. 23, no. 1, pp. 69-75, 2008.

[3] E. Aytaç Adalı and A. Tuş Işık, "Bir Tedarikçi Seçim Problemi İçin SWARA ve WASPAS Yöntemlerine Dayanan Karar Verme Yaklaşımı," Int. Rev. Econ. Manag., vol. 5, no. 4, pp. 56-77, 2017.

[4] A. Özdemir, "Ürün Grupları Temelinde Tedarikçi Seçim Probleminin Ele Alınması ve Analitik Hiyerarşi Süreci İle Çözümlenmesi," Afyon Kocatepe Üniversitesi İ.İ.B.F. Derg., vol. 12, no. 1, pp. 55-84, 2010.

[5] M. Alimardani, S. Hashemkhani Zolfani, M. H. Aghdaie, and J. Tamošaitienè, "A novel hybrid SWARA and VIKOR methodology for supplier selection in an agile environment," Technol. Econ. Dev. Econ., vol. 19, no. 3, pp. 533-548, 2013.

[6] R. H. Kouchaksaraei, S. H. Zolfani, and M. Golabchi, "Glasshouse locating based on SWARACOPRAS approach,” Int. J. Strateg. Prop. Manag., vol. 19, no. 2, pp. 111-122, 2015.

[7] M. K. Ghorabaee, E. K. Zavadskas, M. Amiri, and A. Esmaeili, "Multi-criteria evaluation of green suppliers using an extended WASPAS method with interval type-2 fuzzy sets," J. Clean. Prod., vol. 137, pp. 213-229, 2016.

[8] E. K. Zavadskas, D. Kalibatas, and D. Kalibatiene, "A multi-attribute assessment using WASPAS for choosing an optimal indoor environment," Arch. Civ. Mech. Eng., vol. 16, no. 1, pp. 76-85, 2016.

[9] E. Çakır, G. Akel, and M. Doğaner, "Türkiye'de Faaliyet Gösteren Özel Alışveriş Sitelerinin Bütünleşik SWARA - WASPAS Yöntemi ile Değerlendirilmesi," Uluslararası İktisadi ve İdari İncelemeler Derg., vol. 2018, no. 18. EYİ Özel Sayıs1, pp. 599-616, 2018.

[10] N. Zarbakhshnia, H. Soleimani, and H. Ghaderi, "Sustainable third-party reverse logistics provider 
evaluation and selection using fuzzy SWARA and developed fuzzy COPRAS in the presence of risk criteria," Appl. Soft Comput. J., vol. 65, pp. 307-319, 2018.

[11] V. Keršuliene, E. K. Zavadskas, and Z. Turskis, "Selection of rational dispute resolution method by applying new step-wise weight assessment ratio analysis (SWARA)," J. Bus. Econ. Manag., vol. 11, no. 2, pp. 243258, 2010.

[12] E. K. Zavadskas, Z. Turskis, J. Antucheviciene, and A. Zakarevicius, "Optimization of weighted aggregated sum product assessment," Elektron. ir Elektrotechnika, vol.
122, no. 6, pp. 3-6, 2012.

[13] E. K. Zavadskas, J. Antucheviciene, J. Šaparauskas, and Z. Turskis, "Multi-criteria assessment of facades' alternatives: Peculiarities of ranking methodology," Procedia Eng., vol. 57, pp. 107-112, 2013.

[14] E. K. Zavadskas, R. Baušys, and M. Lazauskas, "Sustainable assessment of alternative sites for the construction of a waste incineration plant by applying WASPAS method with single-valued neutrosophic set," Sustainability, vol. 7, pp. 15923-15936, 2015. 